Obere Extremität 2021 · 16:192-197

https://doi.org/10.1007/s11678-021-00653-w

Received: 28 April 2021

Accepted: 15 June 2021

Published online: 2 August 2021

(c) The Author(s) 2021

\title{
Internal bracing in the treatment of elbow instabilities
}

\author{
Alexander Ellwein ${ }^{1,2} \cdot$ Helmut Lill' $\cdot$ Tomas Smith ${ }^{2} \cdot$ Rony-Orijit DeyHazra' \\ Mara Warnhoff' · Gunnar Jensen' \\ ' Department for Orthopaedic Surgery and Traumatology, DIAKOVERE Friederikenstift, Hannover, Germany \\ ${ }^{2}$ Department for Orthopaedic Surgery, Medical School Hannover, DIAKOVERE Annastift, Hannover, \\ Germany
}

\section{Abstract}

Internal bracing is an augmentation of ligament repair or reconstruction using a nonabsorbable suture tape. The suture reinforcement of the ligament is intended to absorb the forces applied to the joint while the ligament repair or reconstruction underneath is healing. The rigidity of the construct is expected to improve primary stability, which should facilitate and accelerate postoperative mobilization and rehabilitation. Nevertheless, internal bracing is a novel treatment and data is limited. Therefore, this review describes the surgical techniques and provides an overview of the current literature regarding acute and chronic instabilities of the medial and lateral elbow treated with internal bracing.

\section{Keywords}

Ligament bracing · Elbow dislocation · Posterolateral instability · LUCL · Ulnar collateral ligament

Internal bracing is an augmentation of ligament repair or reconstruction using a nonabsorbable suture tape. It is an already well-established, safe and effective treatment in other joints such as the knee or ankle $[1,2]$. The idea of internal bracing is a bridging concept, augmenting the ligament repair or reconstruction. Suture reinforcement of the ligament is intended to absorb the forces applied to the joint while the ligament repair or reconstruction beneath is healing. Furthermore, the rigidity of the construct is expected to improve primary stability, which would facilitate and accelerate postoperative mobilization and rehabilitation. Due to the high primary stability it achieves, internal bracing might also be an alternative to the application of a hinged elbow fixator in highgrade instabilities. Nevertheless, the use of internal bracing in elbow instabilities is a novel treatment and data is limited. Therefore, this review describes the surgical techniques and provides an overview of the current literature regarding acute and chronic instabilities of the medial and lateral elbow treated with internal bracing.

\section{Lateral elbow instability}

Elbow dislocation is the second most common dislocation of the major joints in adults with an incidence of 5.2 per 100,000 person-years [3]. O'Driscoll described the trauma mechanism of elbow dislocation as a fall on the outstretched arm with axial compression, valgus moment and external rotation of the forearm [4]. The softtissue injury pattern always starts laterally with a rupture of the lateral ulnar collateral ligament (LUCL) and progresses over the anterior and posterior capsule to the medial collateral ligament (MCL) [5]. Simple elbow dislocations without concomitant bony injuries can be treated non-operatively in the majority of cases [6-8], since secondary stabilizers such as the extensor muscles can stabilize the elbow joint [9, 10]. If the elbow cannot be stabilized due to insufficiency of the LUCL and secondary stabilizers, posterolateral rotatory instability-the most common instability of the elbow-results $[4,5,11]$.

For acute posterolateral rotatory instability, ligament repair is recommended. Since the LUCL ruptures in most cases at 


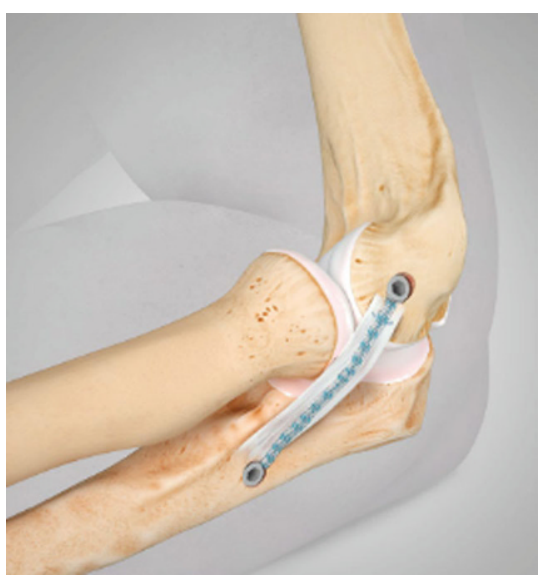

Fig. 1 \& Lateral ulnar collateral ligament repair with additional internal bracing (with kind permission from [39])

its humeral origin [12], humeral LUCL repair is performed using suture anchors or transosseous sutures [13-17]. With an increasing interval between trauma and surgery the ruptured ligament loses its potential to heal. Therefore, an LUCL reconstruction, e.g. with an allo- or autograft, is indicated for these chronic situations. However, this interval is the subject of discussion. While some surgeons define an interval of 21 days as the limit [13], Daluiski et al. present good results even after repair delayed for more than 30 days [14]. To secure LUCL repair or reconstruction, the elbow can be immobilized for a short period of time. The elbow is then mobilized with a hinged elbow brace and limited range of motion without weightbearing for at least 6 weeks $[18,19]$.

Internal bracing is expected to improve primary stability and therefore to facilitate postoperative rehabilitation. Bhide and Greiner published their technique for LUCL repair in 2018 [20]. LUCL repair with additional internal bracing is performed through the Kocher interval. After a skin incision from the lateral epicondyle distally and splitting of the fascia, the joint is approached by blunt dissection between the anconeus muscle and extensor carpi ulnaris muscle. The LUCL is identified and reinforced on the humeral side. Furthermore, the ulnar insertion of the LUCL at the supinator crest, which is estimated at the level of the radial neck at the ulna, is identified. A drill hole is implemented at the supinator crest and a suture tapeloaded $3.5-\mathrm{mm}$ suture anchor is inserted.
The humeral centre of rotation is then defined, which is the most critical step of this surgery. The humeral centre of rotation is marked with a k-wire. The suture tape is wrapped around the k-wire and temporarily fixed with a clamp. If the suture tape is now constantly tensed over the full range of motion, the humeral centre of rotation is optimally targeted. After drilling a hole into the humeral centre of rotation, the elbow is reduced and flexed to $60^{\circ}$. A 4.75$\mathrm{mm}$ suture anchor loaded with the suture tape and sutures of the reinforced native LUCL is advanced into the hole (ס Fig. 1).

The authors' study group performed a biomechanical evaluation, comparing LUCL repair with and without additional internal bracing [21]. While LUCL repair without internal bracing failed at $12.1 \mathrm{Nm}$, the maximum load-to-failure for the internal bracing groups was $26.6 \mathrm{Nm}$ and $23.2 \mathrm{Nm}$, and therefore significantly higher $(p<0.05)$. This significant increase in primary stability allows early functional treatment without bracing and limitations in range of motion. Furthermore, two different techniques for humeral fixation of the LUCL repair with additional internal bracing were compared. Anatomically, the LUCL is part of the lateral collateral ligament (LCL) complex, inserting posterolateral of the centre of rotation at the radial epicondyle [22]. Therefore, in group 1 the internal bracing was inserted in the humeral centre of rotation and an additional suture anchor was placed posterolaterally for the repair of the LUCL, in order to achieve the most anatomical situation. However, in routine clinical practice, there is no sole rupture of the fibres of the LUCL. The rupture involves the LCL complex, which is essentially isometric. Therefore, fixation of the internal bracing and ligament repair at the centre of rotation appeared to be appropriate (group 2; - Fig. 2).

Both techniques showed no difference regarding their biomechanical properties either during cyclic loading or in terms of their maximum load-to-failure. Thus, a one-anchor fixation at the humerus is sufficient and saves implant costs. However, on the ulnar side, multiple failures of the 3.5-mm polyether ether ketone (PEEK) suture anchor during insertion were observed. Probably due to the hard cortical bone, the thread of the anchor failed and it was no longer possible to insert the anchor. The increase from 14 to 24 anchors $(+71 \%)$ also needs to be considered as a cost factor. Therefore, alternative fixation techniques, i.e. the use of a cortical button, need to be discussed. Alternatively, the size of the drill hole needs to be increased, without knowledge regarding the consequences on the stability of the anchor. Finally, while the laxity of the internal bracing was comparable to that of the native LUCL during mid-range of motion, laxity was reduced at maximum flexion and extension. Although the centre of rotation was critically determined, this might be due to the absence of an isometric insertion of the LUCL [23]. Further investigations are necessary to evaluate the impact of the increased pressure on the joint regarding the clinical outcome.

Melbourne et al. also compared LUCL repair with and without internal bracing [24]. The additional augmentation significantly increased resistance to rotational loads due to higher load-to-failure. Regarding the failure modes, different mechanisms were observed. While LUCL repair failed predominantly due to a suture pulling through the repaired ligament, internal bracing failed due to a humeral anchor pullout. Additionally, the authors observed a cutting of the suture tape through the bone [21].To further improve this treatment, humeral fixation should be the focus of further research.

Melbourne et al. also investigated the influence of internal bracing on LUCL reconstruction using a long palmar graft [24]. The internal brace significantly increased the maximum load-to-failure. Although not yet to a significant extent, the authors also observed an increase in stability after internal bracing in LUCL reconstruction [25]. This might be of interest especially for revision surgery after failed LUCL reconstruction. Although recurrent instability after LUCL reconstruction is a rare complication (8\%) [17], almost half of the patients undergoing revision surgery after LUCL reconstruction complain of persistent instability and/or poor functional results. Therefore, internal bracing can be an additional stabilizing factor for these patients. 

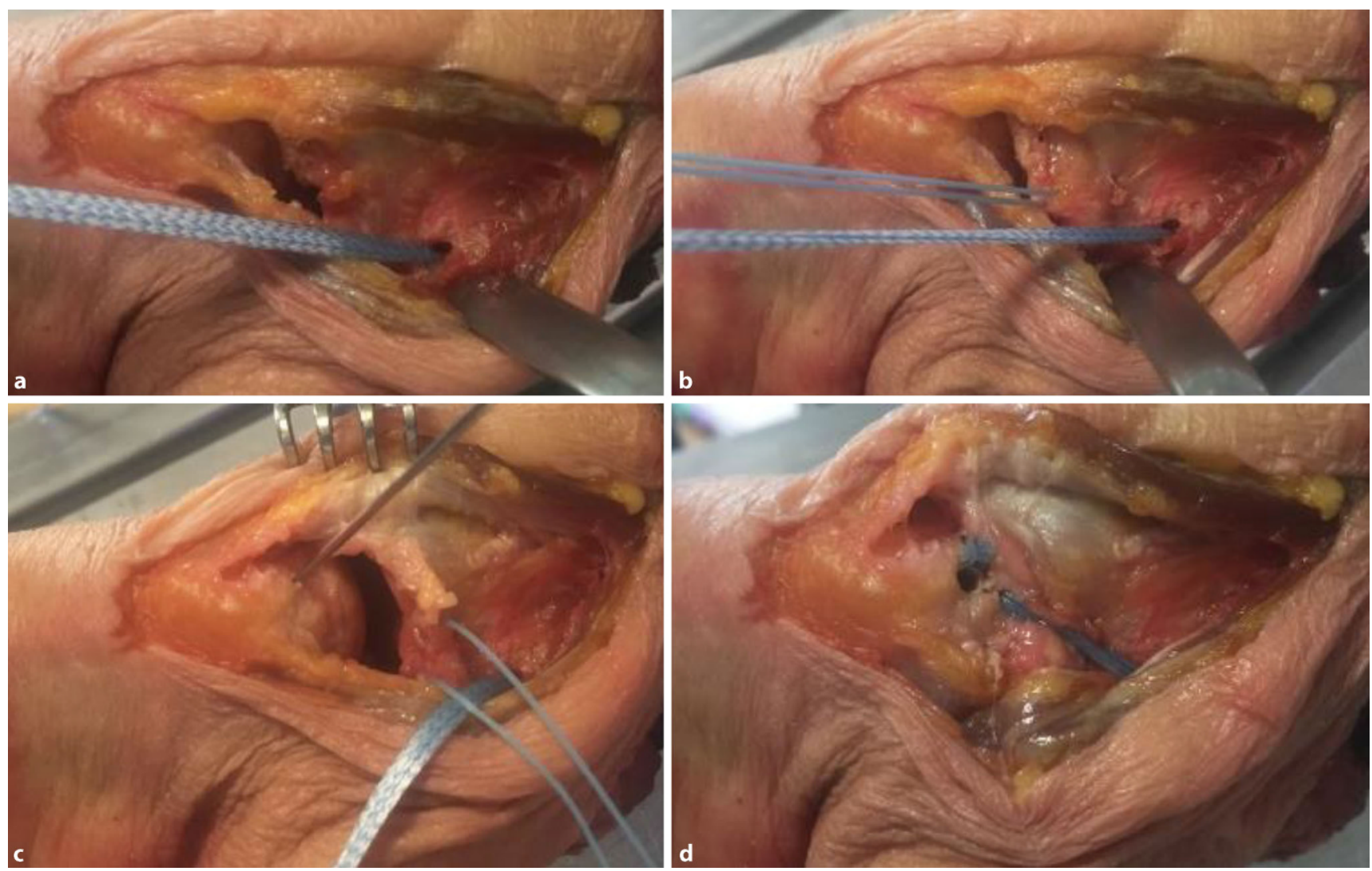

Fig. $2 \Delta$ Lateral ulnar collateral ligament (LUCL) repair with additional internal bracing. a Insertion of the suture tape at the ulnar on the same level of the radial neck. $b$ Suturing of the ruptured lateral collateral ligament complex. $c$ Determination of the humeral centre of rotation. $d$ Final result with the internal bracing lying on top of the LUCL repair

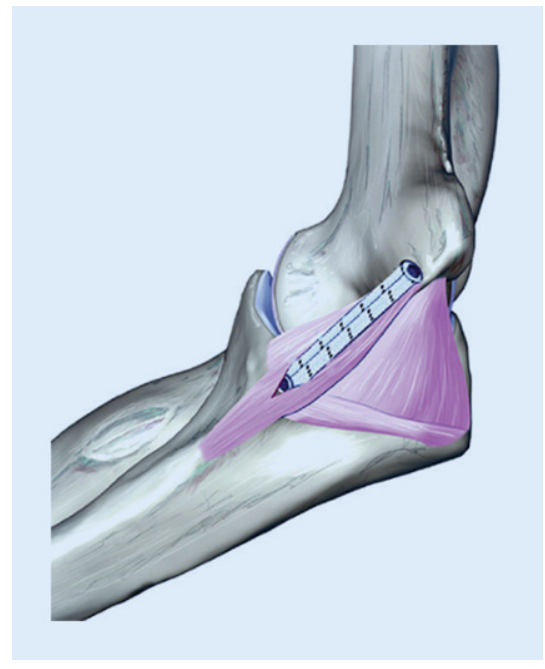

Fig. $3 \Delta$ Medial collateral ligament repair with additional internal bracing (with kind permission from [40])
Scheiderer et al. compared LUCL repair with additional internal bracing with LUCL reconstruction for subacute instabilities. Both treatments restored posterolateral stability comparable to the intact condition of the LUCL. Therefore, internal bracing can be an alternative in delayed LUCL repair without the need for graft harvesting.

Greiner et al. are the only investigators to date presenting clinical results after LUCL repair with additional augmentation. A total of 17 patients with acute and subacute simple and complex elbow dislocations were followed for a mean of 10 months. All patients presented with a stable elbow and a range of motion from $10^{\circ}$ to $130^{\circ}$. Good clinical results were observed with a Disabilities of the Arm, Shoulder and Hand (DASH) score of 18.5 points and Mayo Elbow Performance Score (MEPS) of 96 points. Only one patient required revision surgery due to elbow stiffness with heterotopic ossifications. Therefore, internal bracing seems to be a safe treatment for elbow instabilities with good functional results and a low complication rate. Furthermore, due to the increased stability through augmentation, early mobilization without brace was performed in all patients. This supports the expectation of the facilitated and accelerated mobilization and rehabilitation. Nonetheless, further comparative studies are necessary.

\section{Medial elbow instability}

Despite the trauma mechanism described by O'Driscoll, Schreiber et al. observed further elbow positions resulting in elbow dislocation [26]. One mechanism involved a valgus moment to an extended elbow, i.e. during wrestling fights with a fixed forearm, suggesting a requisite disruption of the MCL. Nonetheless, the most common cause for injury of the MCL is repetitive overloading in overhead throwing athletes, whereby the MCL is injured as the primary soft tissue restraint to valgus stress 

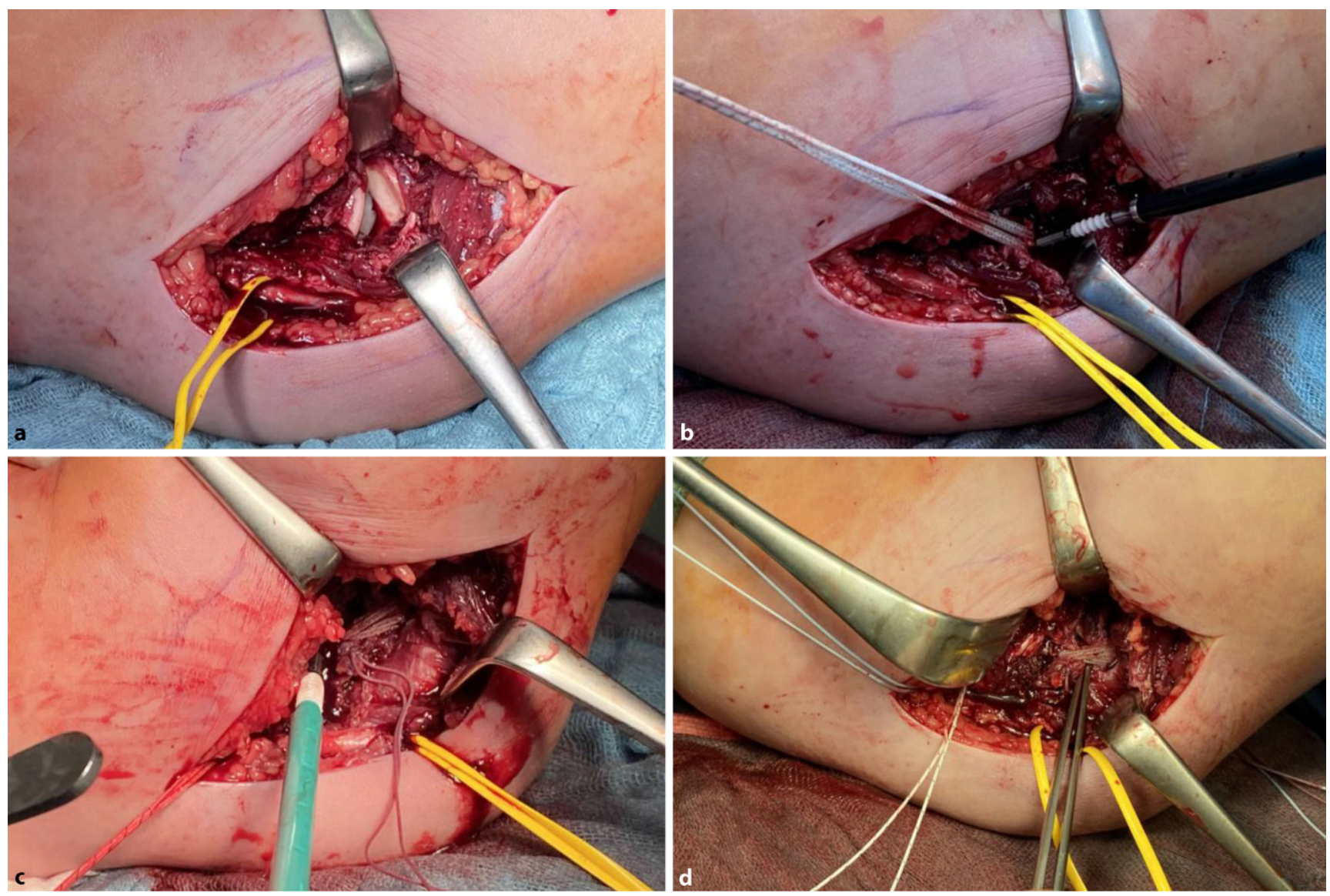

Fig. $4 \Delta$ Medial collateral ligament $(\mathrm{MCL})$ repair with additional internal bracing. a Medial instability with rupture of the flexors and anterior bundle of the MCL. $b$ Insertion of the suture tape at the sublime tubercle. cHumeral fixation of the internal bracing. d Final result with the internal bracing lying on top of the MCLrepair

[27]. The injury classically affects baseball pitchers and is therefore well analyzed in the Anglo-American literature. Although non-operative management is an option especially in partial ruptures, faster return to play makes operative care of MCL injuries desirable for these athletes $[28,29]$. Initially, treatment focused on direct ligament repair, but the results were not satisfying with an overall $0 \%-63 \%$ return to previous or higher level of competition $[30,31]$. In 1986, Jobe et al. described the first successful MCL reconstruction in a Major League Baseball pitcher [32]. Since then, multiple modifications of the Jobe technique have been reported, with improved outcomes and return to play rates of $68-95 \%$, resulting in a strong preference for reconstruction [33]. The rising incidence of $M C L$ injuries in younger athletes has led to renewed interest in $\mathrm{MCL}$ repair, since those patients typically lack the chronic degeneration found in older athletes. Furthermore, repair forgoes the need for graft harvesting, including the donor-site morbidity issues. In these cases, $M C L$ repair with additional internal bracing appears to be an option, improving primary stability and accelerating rehabilitation (- Fig. 3).

The technique for MCL repair with additional internal bracing (• Fig. 4) was first described by Dugas et al. [33]. After isolation and protection of the ulnar nerve, the MCL is approached through a flexorsplitting approach ("Hotchkiss approach"). The ulnar tunnel is centred at the sublime tubercle apex. A 3.5-mm suture anchor loaded with a 2-mm suture tape and No. 0 non-absorbable suture is advanced into the hole. The MCL rupture is repaired by the free ends of the sutures, tying it to its native insertion. A further tunnel is drilled at the humeral centre of rotation at the native $M C L$ footprint. After reducing the elbow joint in $20^{\circ}$ flexion, a further 3.5$\mathrm{mm}$ suture anchor loaded with the suture tape is advanced into the humeral centre of rotation. Overtensioning of the construct has to be avoided.

There are four biomechanical studies to date comparing $\mathrm{MCL}$ repair with additional internal bracing with $\mathrm{MCL}$ reconstruction, all with a comparable biomechanical setup. Dugas et al. and Jones et al. demonstrated significantly greater resistance to gapping for augmented repair compared with reconstruction [33, 34]. Nonetheless, time-zero properties were comparable between the treatments. Bachmaier et al. also compared the two treatment groups with the native situation. Rotational resistance $(p<0.001)$ and residual torque $(p<0.001)$ were significantly higher after augmented repair, with restoration of the native function. MCL reconstruction revealed similar initial stiffness and residual torque compared with an intact ligament, but steadily decreased with higher valgus rotations. Although the aforementioned studies showed a significant difference, Boendorfer et al. did not find any dif- 
ferences for gapping, valgus opening or failure torque [35].

Leasure et al. biomechanically evaluated $\mathrm{MCL}$ reconstruction using a modified Jobe technique and a hybrid technique, adding additional internal bracing to the MCL reconstruction [36]. During cyclic loading, the hybrid construct showed significantly reduced gap formation $(0.43 \mathrm{~mm} \pm 0.17)$ compared with reconstruction $(0.58 \mathrm{~mm} \pm 0.14)(p=0.017)$. Although not statistically significant, the failure torque for the hybrid technique $(25.1 \mathrm{Nm})$ was higher than for reconstruction $(21.0 \mathrm{Nm})(p=0.058)$. A larger sample size might have produced a significant difference due to a false-negative type II error.

Bernholt et al. performed a comparable biomechanical evaluation of $\mathrm{MCL}$ reconstruction with and without internal bracing, but also compared the results the native state of the MCL [37]. The study demonstrated that $M C L$ reconstruction with additional internal bracing improved time-zero stiffness $(4.0 \mathrm{Nm} / \mathrm{deg}$ vs. $3.0 \mathrm{Nm} / \mathrm{deg} ; p=0.044)$ and maximum failure torque (35.5 Nm vs. $18.3 \mathrm{Nm} ; p<0.001$ ) compared to $\mathrm{MCL}$ reconstruction alone. They also demonstrated that MCL reconstruction with additional internal bracing restored biomechanical properties more closely to that of the native MCL.

Overall, the addition of internal bracing for $M C L$ reconstruction demonstrates improved valgus stability as compared to $\mathrm{MCL}$ reconstruction alone. Therefore, the graft can be protected by the internal bracing, allowing for more aggressive rehabilitation and less time to return to play. Furthermore, the hybrid construct replicates the native state more closely. However, the improved stability could also restrict motion and adversely affect the environment of the joint. Therefore, further clinical investigations are necessary.

There are no clinical studies to date evaluating the outcome data after $\mathrm{MCL}$ repair or reconstruction with additional internal bracing. Only Wilk et al. published their experience during rehabilitation for patients treated with additional internal bracing based on the treatment of more than 350 athletes. Overall elbow motion progressed faster after MCL repair with internal bracing with an expected full range of motion after 4 weeks, compared to 6 weeks without internal bracing. All further rehabilitation drills were performed earlier, resulting in a return-to-play time of approximately 5 months, almost 7 months faster than following $\mathrm{MCL}$ reconstruction [38].

\section{Conclusion}

Internal bracing is a novel technique to augment ligament repair or reconstruction. Biomechanical studies showed improved primary stability of ligament repair with additional internal bracing in comparison to sole repair or reconstruction. Likewise for reconstruction with augmentation, stability is increased compared to reconstruction without. This results in an acceleration of postoperative rehabilitation with a faster return to daily life or sport. The high stability of internal bracing raises the question of the necessity of a hinged elbow fixator. Furthermore, in subacute trauma without degenerative changes of the ligaments, ligament repair with internal bracing can be an alternative to reconstruction without the requirement of graft harvesting. However, optimal fixation is still a challenge that needs further evaluation to improve this procedure. There is a lack of clinical evidence to date regarding the clinical outcome or complications in relation to internal bracing of the elbow. Therefore, further clinical studies are necessary to evaluate this treatment and identify the optimal indication for this innovative additional procedure.

Corresponding address

\section{Dr. Alexander Ellwein}

Department for Orthopaedic Surgery and Traumatology, DIAKOVERE Friederikenstift Humboldtstr. 5, 30169 Hannover, Germany alexander.ellwein@diakovere.de

\section{Declarations}

Conflict of interest. A. Ellwein, H. Lill, T. Smith, R.O. DeyHazra, M. Warnhoff and G. Jensen declare that they have no competing interests.

For this article no studies with human participants or animals were performed by any of the authors. All studies performed were in accordance with the ethical standards indicated in each case.
Open Access. This article is licensed under a Creative Commons Attribution 4.0 International License, which permits use, sharing, adaptation, distribution and reproduction in any medium or format, as long as you give appropriate credit to the original author(s) and the source, provide a link to the Creative Commons licence, and indicate if changes were made. The images or other third party material in this article are included in the article's Creative Commons licence, unless indicated otherwise in a credit line to the material. If material is not included in the article's Creative Commons licence and your intended use is not permitted by statutory regulation or exceeds the permitted use, you will need to obtain permission directly from the copyright holder. To view a copy of this licence, visit http://creativecommons.org/licenses/by/4.0/.

\section{References}

1. Dabis J, Wilson A (2019) Repair and augmentation with internal brace in the multiligament injured. Knee Clin Sport Med 38:275-283. https://doi.org/ 10.1016/j.csm.2018.11.008

2. Lewis T, Jseph A, Patel A et al (2020) Modified Broström repair with suture tape augmentation for lateral ankle instability: a systematic review. Foot Ankle Surg. https://doi.org/10.1016/j.fas.2020.12. 004

3. Stoneback JW, Owens BD, Sykes J et al (2012) Incidence of elbow dislocations in the United States population. J Bone Joint Surg Am 94:240-245

4. O'Driscoll SW, Bell DF, Morrey BF (1991) Posterolateral rotatory instability of the elbow. J Bone Joint Surg Am 73:440-446

5. O'Driscoll S, Morrey B, Korinek S, An K (1992) Elbow subluxation and dislocation-a spectrum of instability. Clin Orthop Relat Res 280:186-197

6. Hackl M, Beyer F, Wegmann K et al (2015) The treatment of simple elbow dislocation in adults - a systematic review. Dtsch Arztebl Int 112:311-319. https://doi.org/10.3238/arztebl. 2015.0311

7. Rafai M, Largab A, Cohen D, Trafeh M (1999) Pure posterior luxation of the elbow in adults: immobilization or early mobilization. A randomized prospective study of 50 cases. Chir Main 18:272-278

8. lordens GIT, Van Lieshout EMM, Schep NWL et al (2017) Early mobilisation versus plaster immobilisation of simple elbow dislocations: results of the FuncsiE multicentre randomised clinical trial. Br J Sport Med 51:531-538. https:// doi.org/10.1136/bjsports-2015-094704

9. O'Driscoll SW, Jupiter JB, King GJ et al (2001) The unstable elbow. Instr Course Lect 50:89-102

10. Safran MR, Baillargeon D (2005) Soft-tissue stabilizers of the elbow. J Shoulder Elbow Surg 14:179S-185S. https://doi.org/10.1016/j.jse.2004. 09.032

11. Dunning CE, Zarzour ZDS, Patterson SD et al (2001) Ligamentous stabilizers against posterolateral rotatory instability of the elbow. J Bone Joint Surg Am 83:1823-1828. https://doi.org/10.2106/ 00004623-200112000-00009

12. McKee MD, Schemitsch EH, Sala MJ, O'Driscoll SW (2003) The pathoanatomy of lateral ligamentous disruption in complex elbow instability. JShoulde Elbow Surg 12:391-396. https://doi.org/10.1016/ S1058-2746(03)00027-2

13. Kim BS, Park KH, Song HS, Park SY (2013) Ligamentous repair of acute lateral collateral ligament rupture of the elbow. J Shoulder Elbow 
Surg 22:1469-1473. https://doi.org/10.1016/j.jse. 2013.06.018

14. Daluiski A, Schrumpf MA, Schreiber JJ et al (2014) Direct repair for managing acute and chronic lateral ulnar collateral ligament disruptions.J Hand Surg Am 39:1125-1129. https://doi.org/10.1016/j. jhsa.2014.02.011

15. Sanchez-Sotelo J, Morrey BF, O'Driscoll SW (2005) Ligamentous repair and reconstruction for posterolateral rotatory instability of the elbow. JBone Joint Surg Br 87:54-61

16. Taylor F, Sims M, Theis J-C, Herbison GP (2012) Interventions for treating acute elbow dislocations in adults. Cochrane Database Syst Rev. https://doi. org/10.1002/14651858.CD007908.pub2

17. Anakwenze OA, Kwon D, O'Donnell E et al (2014) Surgical treatment of posterolateral rotatory instability of the elbow. Arthroscopy 30:866-871. https://doi.org/10.1016/j.arthro.2014.02.029

18. Hackl $M$, Leschinger $T$, Uschok $S$ et al (2017) Rehabilitation of elbow fractures and dislocations. Obere Extrem 12:201-207. https://doi.org/10. 1007/s11678-017-0425-1

19. Jones KJ, Dodson CC, Osbahr DC et al (2012) The docking technique for lateral ulnar collateral ligament reconstruction: surgical technique and clinical outcomes. J Shoulder Elbow Surg 21:389-395. https://doi.org/10.1016/j.jse.2011. 04.033

20. Bhide PP, Greiner S (2018) Ligament bracing of the elbow. Obere Extrem 13:218-220. https://doi.org/ 10.1007/s11678-018-0463-3

21. Ellwein $A$, Füßler L, Ferle $M$ et al (2021) Suture tape augmentation of the lateral ulnar collateral ligament increases load to failure in simulated posterolateral rotatory instability. Knee Surg Sports Traumatol Arthrosc 29:284-291. https:// doi.org/10.1007/s00167-020-05918-5

22. Morrey BF, An K (1985) Functional anatomy of the ligaments of the elbow. Clin Orthop Relat Res. https://doi.org/10.1016/B978-0-323-286831.00046-1

23. Goren D, Budoff JE, Hipp JA (2010) Isometric placement of lateral ulnar collateral ligament reconstructions: a biomechanical study. Am J Sports Med 38:153-159. https://doi.org/10.1177/ 0363546509346049

24. Melbourne C, Cook JL, Della Rocca GJ et al (2020) Biomechanical assessment of lateral ulnar collateral ligament repair and reconstruction with or without internal brace augmentation. JSES Int 4:224-230. https://doi.org/10.1016/j.jseint.2020. 01.011

25. Ellwein A, Becker S, Nebel D et al (2021) Biomechanical comparison of lateral collateral ligament reconstruction with and without additional internal bracing using a three-dimensional elbow simulator. Clin Biomech. https://doi.org/10.1016/ j.clinbiomech.2020.105236

26. Schreiber JJ, Warren RF, Hotchkiss RN, Daluiski A (2013) An online video investigation into the mechanism of elbow dislocation. J Hand Surg Am 38:488-494. https://doi.org/10.1016/j.jhsa.2012. 12.017

27. Fleisig GS, Andrews JR, Dillman CJ, Escamilla RF (1995) Kinetics of baseball pitching with implications about injury mechanisms. Am J Sports Med 23:233-239. https://doi.org/10.1177/ 036354659502300218

28. Ford GM, Genuario J, Kinkartz J et al (2016) Returnto-play outcomes in professional baseball players after medial ulnar collateral ligament injuries. Am J Sports Med 44:723-728. https://doi.org/10.1177/ 0363546515621756

\section{Internal Bracing in der Behandlung von Ellenbogeninstabilitäten}

Beim „internal bracing“ handelt es sich um eine zusätzliche Augmentation refixierter oder rekonstruierter Bandstrukturen mit einem nichtresorbierbaren Faden, also einem künstlichen Band. Die Augmentation soll die auf den Ellenbogen wirkenden Kräfte aufnehmen, sodass die darunter liegende Refixation oder Rekonstruktion einheilen kann. Aufgrund der Rigidität des künstlichen Bandes wird eine höhere Primärstabilität erwartet, welche die postoperative Mobilisation und Rehabilitation erleichtern und beschleunigen würde. Die Datenlage zu diesem modernen Verfahren ist jedoch noch unzureichend. Ziel dieser Übersichtsarbeit ist es, die Operationstechniken zu beschreiben sowie einen Überblick über die aktuelle Literatur hinsichtlich des Einsatzes künstlicher Bänder in der Versorgung medialer und lateraler Ellenbogeninstabilitäten zu präsentieren.

\section{Schlüsselwörter}

Künstliche Bänder · Ellenbogenluxation · Posterolaterale Instabilität · LUCL · Ulnares Seitenband

29. Walker CM, Genuario JW, Houck DA et al (2021) Return-to-play outcomes in professional baseball players after nonoperative treatment of incomplete medial ulnar collateral ligament injuries: a long-term follow-up study. Am J Sports Med 49:1137-1144. https://doi.org/10.1177/ 0363546521996706

30. Azar F, Adnrews J, Wilk K, Groh D (2000) Operative treatment of ulnar collateral ligament insufficiency of the elbow in female athletes. Am J Sports Med 28:16-23. https://doi.org/10.1177/ 0363546505281240

31. Andrews JR, Timmerman LA (1995) Outcome of elbow surgery in professional baseball players. Am J Sports Med 23:407-413. https://doi.org/10. $1177 / 036354659502300406$

32. Jobe FW, Stark H, Lombardo SJ (1986) Reconstruction of the ulnar collateral ligament in athletes. J Bone Joint Surg Am 68:1158-1163. https://doi. org/10.2106/00004623-198668080-00004

33. Dugas JR, Walters BL, Beason DP et al (2016) Biomechanical comparison of ulnar collateral ligament repair with internal bracing versus modified jobe reconstruction. Am J Sports Med 44:735-741. https://doi.org/10.1177/ 0363546515620390

34. Jones CM, Beason DP, Dugas JR (2018) Ulnar collateral ligament reconstruction versus repair with internal bracing: comparison of cyclic fatigue mechanics. Orthop J Sports Med 6:1-7. https:// doi.org/10.1177/2325967118755991

35. Bodendorfer BM, Looney AM, Lipkin SL et al (2018) Biomechanical comparison of ulnar collateral ligament reconstruction with the docking technique versus repair with internal bracing. Am J Sports Med 46:3495-3501. https:// doi.org/10.1177/0363546518803771

36. Leasure J, Reynolds K, Thorne M et al (2019) Biomechanical comparison of ulnar collateral ligament reconstruction with a modified docking technique with and without suture augmentation. Am J Sports Med 47:928-932. https://doi.org/10. 1177/0363546518820304

37. Bernholt DL, Lake SP, Castile RM et al (2019) Biomechanical comparison of docking ulnar collateral ligament reconstruction with and without an internal brace. J Shoulder Elbow Surg 28:2247-2252. https://doi.org/10.1016/j.jse.2019. 04.061

38. Cain EL, Andrews JR, Dugas JRetal (2010) Outcome of ulnar collateral ligament reconstruction of the elbow in 1281 athletes: results in 743 athletes with minimum 2-year follow-up. Am J Sports Med 38:2426-2434. https://doi.org/10.1177/ 0363546510378100

39. GreinerS, Koch M, Kerschbaum Metal (2019) Repair andaugmentation of the lateral collateral ligament complex using internal bracing in dislocations and fracture dislocations of the elbow restores stability and allows early rehabilitation. Knee Surg Sports Traumatol Arthrosc 27:3269-3275. https://doi. org/10.1007/s00167-019-05402-9

40. Bachmaier S, Wijdicks CA, Verma NN et al (2020) Biomechanical functional elbow restoration of acute ulnar collateral ligament tears: the role of internal bracing on gap formation and repair stabilization. Am J Sports Med 48:1884-1892. https://doi.org/10.1177/0363546520921174 